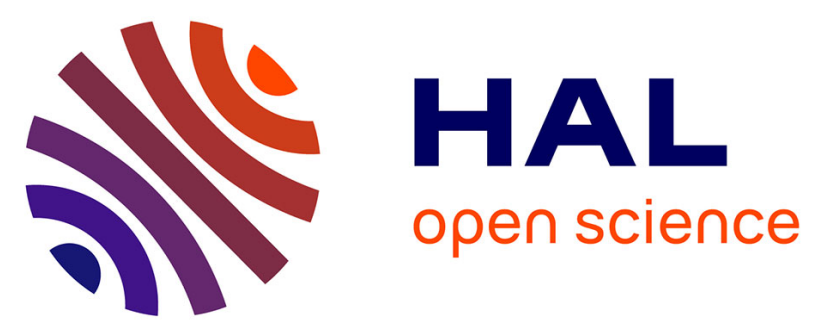

\title{
Parametric Analysis of an Active Winglet Concept for High Aspect Ratio Wing Using CFD/CSM Computations
}

Martin Delavenne, Bernard Barriety, Fabio Vetrano, Valérie Ferrand, Michel Salaün

\section{To cite this version:}

Martin Delavenne, Bernard Barriety, Fabio Vetrano, Valérie Ferrand, Michel Salaün. Parametric Analysis of an Active Winglet Concept for High Aspect Ratio Wing Using CFD/CSM Computations. AIAA AVIATION 2020 FORUM, Jun 2020, Virtual event, United States. pp.1-17, 10.2514/6.20202662. hal-03391176

\section{HAL Id: hal-03391176 https://hal.science/hal-03391176}

Submitted on 21 Oct 2021

HAL is a multi-disciplinary open access archive for the deposit and dissemination of scientific research documents, whether they are published or not. The documents may come from teaching and research institutions in France or abroad, or from public or private research centers.
L'archive ouverte pluridisciplinaire HAL, est destinée au dépôt et à la diffusion de documents scientifiques de niveau recherche, publiés ou non, émanant des établissements d'enseignement et de recherche français ou étrangers, des laboratoires publics ou privés. 


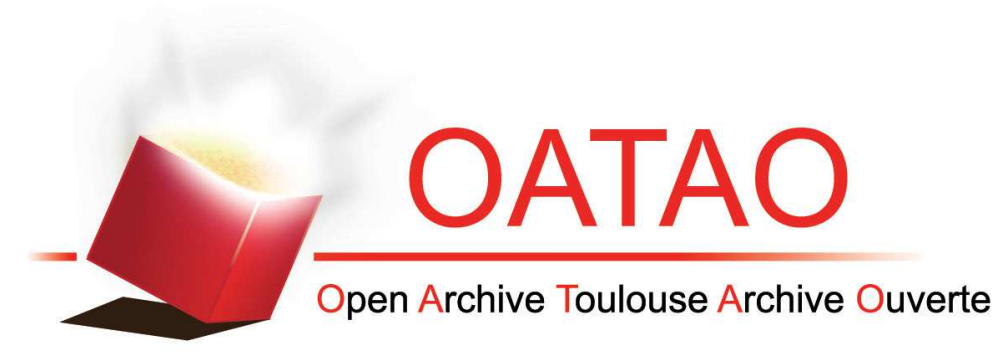

\section{Open Archive Toulouse Archive Ouverte (OATAO)}

OATAO is an open access repository that collects the work of some Toulouse researchers and makes it freely available over the web where possible.

This is an author's version published in: https://oatao.univ-toulouse.fr/28454

Official URL: https://doi.org/10.2514/6.2020-2662

\section{To cite this version :}

Delavenne, Martin and Barriety, Bernard and Vetrano, Fabio and Ferrand, Valérie and Salaün, Michel Parametric Analysis of an Active Winglet Concept for High Aspect Ratio Wing Using CFD/CSM Computations. (2020) In: AIAA AVIATION 2020 FORUM, 15 June 2020 - 19 June 2020 (Virtual event, United States).

Any correspondence concerning this service should be sent to the repository administrator: tech-oatao@listes-diff.inp-toulouse.fr 


\title{
Parametric Analysis of an Active Winglet Concept for High Aspect Ratio Wing Using CFD/CSM Computations
}

\author{
Martin Delavenne*, Bernard Barriety ${ }^{\dagger}$ and Fabio Vetrano ${ }^{\ddagger}$ \\ Airbus Operations SAS, Toulouse, 31060, France \\ Valérie Ferrand ${ }^{\S}$ \\ ISAE-SUPAERO, Université de Toulouse, Toulouse, 31400, France \\ Michel Salaun ${ }^{\text {II }}$
}

ICA, Université de Toulouse, ISAE-SUPAERO, MINES ALBI, UPS, INSA, CNRS, Toulouse, 31400, France

This paper presents a parametric analysis of an active winglet concept applied to a high aspect ratio wing. The technology studied here only consists in a single degree of freedom wing-tip whose only the cant angle deflection can be controlled. The main parameters under study are the hinge line location and its orientation with respect to the longitudinal axis of the aircraft. High-fidelity aerodynamic and structural computations are used to assess the impact of the device on both drag and loads. The influence of cant angle deflections on flutter characteristics is also evaluated. First a "wing only" configuration is studied and the results are compared with complete aircraft computations to take into account the contributions due to the trim. It is shown that the hinge line parameters highly influence the drag evolution with cant angle but with limited impact on the minimum area - in which we are interested in. Loads are significantly impacted by both cant variations and hinge line geometry. Regarding dynamic characteristics, the mode sequence is dependent on the cant deflection and massively impacts flutter onset.

\section{Nomenclature}

$\begin{array}{ll}\text { AoA } & =\text { Angle of Attack } \\ \mathrm{AR} & =\text { Aspect Ratio } \\ \mathrm{b} & =\text { Aircraft semi-span } \\ \mathrm{c} & =\text { Aircraft mean aerodynamic chord } \\ C_{d} & =\text { Drag coefficient } \\ C_{d, i} & =\text { Induced drag coefficient } \\ C_{d, v} & =\text { Viscous drag coefficient } \\ C_{d, w} & =\text { Wave drag coefficient } \\ \mathrm{CFD} & =\text { Conputational Fluid Dynamics } \\ \mathrm{CSM} & =\text { Computational Structural Mechanics } \\ \delta & =\text { Winglet cant angle } \\ f & =\text { Oscillations frequency } \\ \mathrm{FEM} & =\text { Finite Element Model } \\ \eta & =\text { Non-dimensional span }(\mathrm{y} / \mathrm{b}) \\ \mathrm{HAR} & =\text { High Aspect Ratio } \\ k & =\text { Reduced frequency } \\ \Lambda_{h i n g e} & =\text { Hinge line orientation } \\ \text { LFD } & =\text { Linear Frequency Domain }\end{array}$

$$
\begin{array}{ll}
\text { MMO } & =\text { Maximum Mach in Operation } \\
\text { MTOW } & =\text { Maximum Take-off Weight } \\
\omega & =\text { Oscillations pulsation } \\
\vec{q} & =\text { Generalized coordinates vector } \\
\rho & =\text { Fluid density } \\
\text { RANS } & =\text { Reynolds Average Navier-Stokes } \\
V_{\infty} & =\text { Upstream speed } \\
\text { VMO } & =\text { Maximum Speed in Operation } \\
\text { WRBM } & =\text { Wing Root Bending Moment }
\end{array}
$$

\footnotetext{
*PhD student, Loads \& Aeroelastics, martin.m.delavenne@ airbus.com.

${ }^{\dagger}$ Loads \& Aeroelastics Engineer, Loads \& Aeroelastics, bernard.barriety@airbus.com.

Loads \& Aeroelastics Engineer, Loads \& Aeroelastics, fabio.vetrano@airbus.com.

$\S$ Associated Professor, Department of Aerodynamics and Propulsion, valerie.ferrand@isae-supaero.fr.

IIProfessor, Department of Strutural Mechanics, michel.salaun@isae-supaero.fr.
} 


\section{Introduction}

THE optimization of the aerodynamic performance, driven mainly by drag, is core business for aircraft manufacturers. According to Prandtl's theory there is two ways to reduce the induced drag on an aircraft [1] once the lift is fixed: First, to adopt an elliptic lift distribution, secondly to increase the wing aspect ratio. Although the simplest, these solutions face several limitations: The detrimental impact on loads and particularly on WRBM due to the elliptic distribution, the airport regulations that imposes a maximum wing span dependent on aircraft categories [2] which constrains the wing plane form. One way to cope with this issue is to increase the deployed span without impacting the plane-form by adding off-plane surfaces known as winglets. Since R. Whitcomb has demonstrated the usefulness of these devices to reduce significantly the induced drag [3], numerous shapes of winglets have been implemented on aircraft and have lead to an average improvement of $4 \%$ of the performances [4]. An alternative is to design high aspect ratio wings to take advantage of the induced drag reduction combined with folding wing-tips to avoid ground penalties, which is the technology adopted for the new B-777X [5]. Whatever the selected solution or combination of solutions exposed here-above, the optimization of the aerodynamic shapes is only valid for a limited range of operational conditions given the fixed configuration of current designs. That results in sub-optimal behaviour in off-design part of the flight domain. To cope with this issue and limit the environmental footprint of civil aviation, more adaptive technologies are under investigations. One of the most popular is the wing morphing, which consists in a continuous control of the wing shape to optimize the performances inside the whole operational envelop [6, 7]. Besides, these versatile configurations are not only able to control the performance but may be used to adapt the load distribution depending on the flight conditions : For stabilized cruise the optimal elliptic distribution is targeted, while for manoeuvre or gust encounter a more inward loading can be adopted to limit the impact on the structure. This could lead to significant weight and fuel savings [8]. The active winglet concept was first patented by Airbus [9] and consists in an articulated wing-tip which allows for cant angle adaptation. The capability to control the deflection of the winglet enables both to increase the span and benefit from the aspect ratio improvement as well as to act on the lift distribution to target the elliptic shape by acting on the wing twist. It is also thought that some loads alleviation capabilities may lead to additional savings as demonstrated in [10] even if the concepts are slightly different. Previous analyses were performed for the Airbus XRF1 model in a retrofit context [11, 12]. They demonstrated that a control of the wing shape was actually achievable but, depending on the stiffness of the wing, the impact on the aerodynamic performances can be significantly damped. This paper explores the impact of the hinge line parameters (location and orientation) on the active winglet efficiency regarding drag and loads control as well as influence on flutter characteristics. The present study focuses on a high aspect ratio version of the wing of the XRF1 model whose plane form and aerodynamic profiles were optimized by the University of Michigan in the frame of a partnership with Airbus [13]. Given its span, a folding wing-tip would be mandatory for this aircraft to respect the limitations corresponding to its airport category. Therefore, the issue here is to determine if a continuous actuation of the wing-tip would be beneficial. To assess the wing deformation and its impact on performances as precisely as possible, high-fidelity computations coupling aerodynamics (CFD) and structural mechanics (CSM) are used, a far-field drag decomposition is used to evaluate the contribution of each of drag components and loads computations are performed. The next paragraph of the paper details those methods and provides more information about the models. The following parts are dedicated to the results and their discussion.

\section{Work Description}

\section{A. Aerodynamic and Structural Models}

\section{Test-case}

For this work, the XRF1 model, an Airbus provided industrial standard multi-disciplinary research test case representing a typical configuration for a long range wide body aircraft is used (Fig. 1). The version under study differs from the "original" one by its high aspect ratio wing $(A R=11.6)$ optimized for multipoint conditions by the University of Michigan [13]. The half-span of the aircraft is $b=1.06 \cdot b_{\max }$, with $b_{\max }$ the airport limit for this aircraft category. That means that a folding wing-tip system would be required to keep the aircraft within the targeted category [2]. For a binary system like the one designed for the B777-X the hinge line is located near to the aerodrome limit to minimize the actuator weight. But for an active device, the location and the orientation of the hinge fix the active part length and it is predictable that it impacts the efficiency of the device. In this study two different locations are analysed. As it will be justified in the results section, the effects of cant angle and hinge location can be analysed considering the wing alone. 
This simplified configuration leads to significant computation time reduction while not degrading the conclusions.

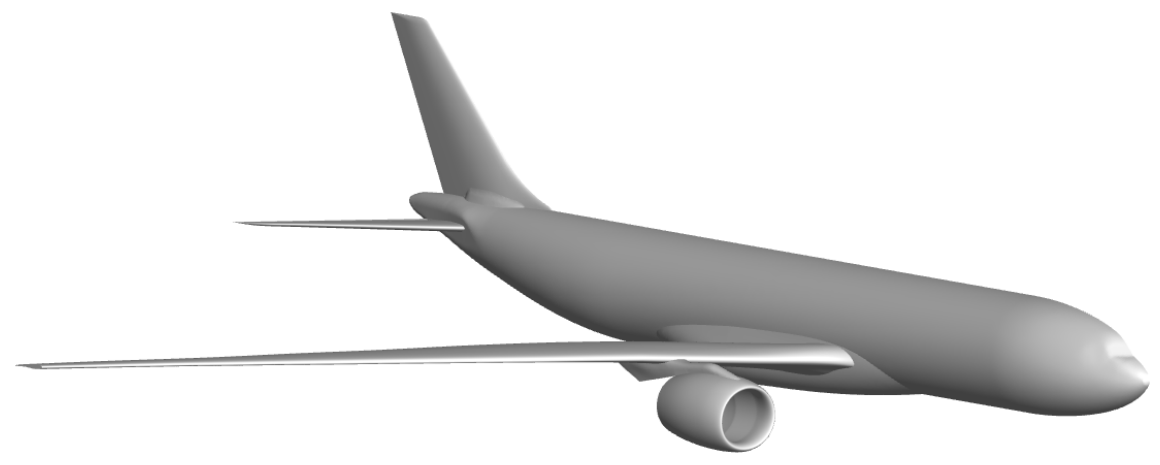

Fig. 1 XRF1 High aspect ratio model

\section{Aerodynamic Model}

As mentioned in the introduction, high-fidelity coupled CFD/CSM computations are carried out in this work. For the wing only configuration the aerodynamic model is composed of a 5 million nodes unstructured grid. To analyse the impact of the winglet deflection on the aerodynamic performances, grids are built for 7 different configurations of cant angles $\delta:\left[-90^{\circ},-60^{\circ},-30^{\circ}, 0^{\circ}, 30^{\circ}, 60^{\circ}, 90^{\circ}\right]$ as illustrated on Fig. 2. Steady RANS equations are solved with TAU, a CFD code developed by the DLR [14]. Regarding turbulence modelling, the classic 2 equations Menter-SST closure model (Shear Stress Transport) is used [15]. Computations are performed for transonic cruise conditions targeting a constant lift coefficient consistent with the aircraft mass case. For the simplified wing only configuration the real lift coefficient is factorised to account for the lift generated by the other components (Fuselage, nacelles, tails) and is reached by adjustment of the AoA.

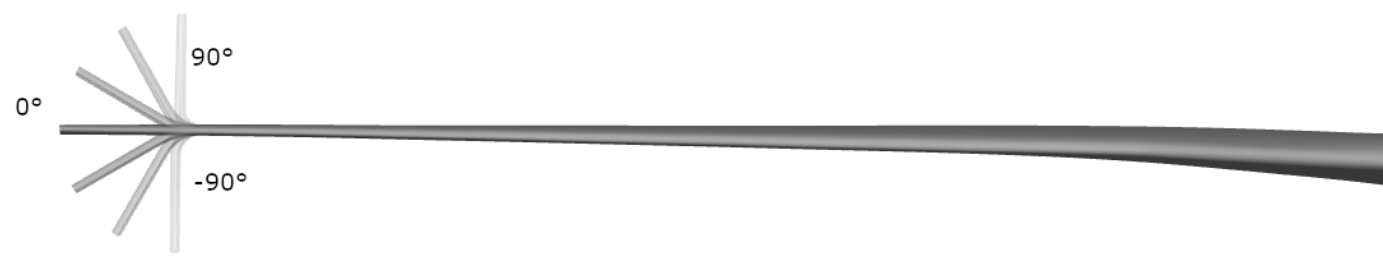

Fig. 2 XRF1 high AR wing with various cant angle deflections of the wing-tip

For the validation phase, the whole aircraft model is used but as only symmetric flight conditions are considered only half the model is built Fig 1 . Here again a constant lift coefficient is targeted and an additional constraint to cancel the pitching moment is considered. The trimming process relies on rigid rotation of the horizontal tail plane and adjustments of the AoA. The engine jet is not accounted for while the nacelles and pylons geometries are taken into account to predict the more accurately as possible the overall drag.

CFD solver is coupled to CSM one (III.A.3) to evaluate the aerodynamic forces on a deformed shape. To do so, mesh is deformed accordingly to structural displacements computed for reference nodes and interpolated to fluid grid using Radial Basis Functions as detailed in [16].

\section{Structural Model}

Regarding the structural part of the analysis, a finite element model of the wing composed of 17,000 nodes is considered. The wing is made of metallic material the weight of the non structural parts are taken into account as distributed punctual masses along the span, particularly fuel distribution can be adjusted to change the mass case under consideration. The wing is clamped at its innermost rib and the outer part is cut at the hinge location to enable for the outermost part to rotate around the hinge line as illustrated on Fig. 3 , the actuator link is modelled as a rigid element. The weight of the folding system is fixed to the constant value of $140 \mathrm{~kg}$ for every configuration and is introduced in the 
model through a mass node at the articulation location. This value is an upper-bound estimation of the actuator weight based on orders of magnitude provided in [17] for the XB-70 Valkyrie folding wing-tips actuation system. The static structural displacements are computed using Nastran code (SOL101). A modal analysis is performed (SOL103) to determined the mode shapes and frequencies to be used for flutter analysis (III.B.3).

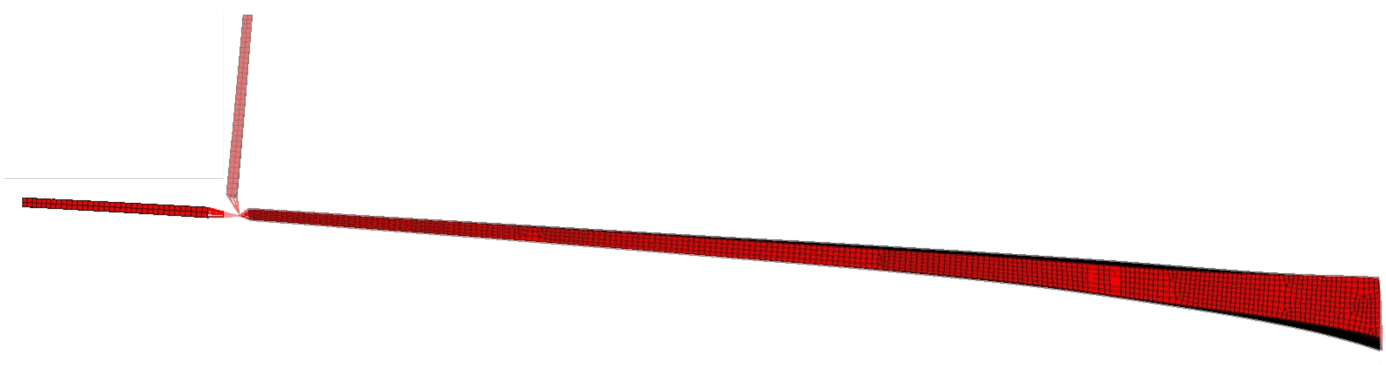

Fig. 3 XRF1 HAR wing FEM model for 2 different cant deflections

For CFD/CSM computation aerodynamic forces, computed with TAU (Sect[III.A.2), must be transferred to the structural reference nodes. The method selected here consists in computing the forces and moments at a given structural location as the sum of forces and moments of the closest aerodynamic nodes. This method is referred as Nearest-Neighbour approach in the literature [16]

\section{B. Performances, Loads and Flutter Computations}

\section{Drag Evaluation}

There are two means to evaluate the drag on an aircraft, the first one consists of the integration of the pressure and shear stress around the surface of the body. This methodology is referred as the near-field drag. In order to get a better insight into the impact of the active winglet on the physical drag components and to complete the analysis a second method, referred as the far-field drag decomposition, is applied. It is based on the work by Destarac and Van der Vooren [18] and segregates the contributions of the different drag components: $C_{d, i}, C_{d, v}$ and $C_{d, w}$. The principle is to consider the momentum equation integrated on a control volume composed by upstream, lateral and downstream surfaces as well as the aircraft surface.

\section{Loads Computation}

Loads must also be assessed to analyse the impact of the active winglet on the wing root bending moment in particular. Aerodynamic forces and moments distribution are computed from CFD/CSM simulations. Several load cases are considered: $1 \mathrm{~g}$ case is explored for several mass cases and a $1.66 \mathrm{~g}$ load factor case is analysed for the design condition mass case. The certification imposes to demonstrate the structural resistance up to $2.5 \mathrm{~g}$ but for those high load factors, associated with high AoA, there are large separated flow areas that make the CFD not predictive. Therefore, in this work the loads computations are limited to conditions with attached flows.

\section{Flutter Computations}

Flutter is an explosive self-sustained oscillation of the structure with catastrophic consequences if not correctly predicted and if it occurs in the flight domain. That is why the certification regulation requires the manufacturers to prove that the aircraft is free from flutter in an extended flight envelop constructed from the diving speed or Mach (depending on the altitude) incremented by a safety margin of $15 \%$ on the equivalent airspeed. The XRF1 HAR wing is optimized taking into account a flutter constraints, the configuration without actuation system should be free from flutter. However, what happens when the winglet must fold and an actuation system is added?

To answer this question the flutter equation (1) is solved for each cant angle deflection of interest using the p-k method [19].

$$
\boldsymbol{A} \cdot \vec{q}+\left(\rho V_{\infty} \boldsymbol{B}+\boldsymbol{D}\right) \cdot \overrightarrow{\dot{q}}+\left(\rho V_{\infty}^{2} \boldsymbol{C}+\boldsymbol{E}\right) \cdot \vec{q}=0
$$


With $\boldsymbol{A}, \boldsymbol{B}, \boldsymbol{C}, \boldsymbol{D}$ and $\boldsymbol{E}$ the mass, the aerodynamic damping and stiffness, the structural damping and stiffness matrices, respectively [20]. Because the aerodynamic matrices depends on the reduced frequency $k=\frac{\omega c}{V_{\infty}}$, the equation is solved iteratively and aerodynamic forces must be assessed for the whole range of $k$. Linearized Frequency Domain (LFD) computations are performed to compute these unsteady aerodynamic forces for reduced frequencies from 0 to 4.0 and for the ten first oscillation modes of the structure. The method relies on the assumption of small harmonic perturbations that allows for the linearization of the RANS equations around the steady state deformation in the time domain. The equations are then transformed to the frequency domain to be solved considering only the first harmonic [21].

\section{Parametric Analysis}

For the parametric analysis two main parameters are retained: The hinge line location along the span and its orientation with respect to the streamwise direction. Table 1 gives the different configurations analysed so far. The winglet span is expressed relatively to the total wing span $b_{\text {winglet }}=b_{\text {winglet, } r e l} \times b$. The deployed total span being constant for all configurations the hinge line is displaced more or less inward when winglet span changes. Hinge line oriented with respect to the streamwise direction (positive values correspond to a clockwise rotation (view from top)). For each span/orientation combination the whole range of cant angle deflections is analysed, drag and loads are computed, and flutter characteristics are assessed.

Table 1 Combination of parameters studied.

\begin{tabular}{|c|c|}
\hline Relative winglets span & Hinge orientation $\Lambda_{\text {hinge }}$ \\
\hline $7 \%$ & $0^{\circ}$ \\
\hline $13 \%$ & $0^{\circ}$ \\
\hline $7 \%$ & $-2.5^{\circ}$ \\
\hline $7 \%$ & $2.5^{\circ}$ \\
\hline
\end{tabular}

The first combination will be considered as the baseline for the rest of the work and in particular its cant $0^{\circ}$ configuration will serve as a reference to compare the results of the other configurations.

For every computation only one mass case corresponding to $90 \%$ of the maximum take-off weight and the design cruise conditions are considered. Therefore the lift coefficient remains unchanged, whatever the configuration, and the angle of attack is adjusted during the CFD/CSM loops to reach this value. For this flight condition the four configurations are compared and the wing only hypothesis is justified. Other flight conditions with extreme masses and altitudes are analysed for the baseline wing only configuration (i.e. $\Lambda_{\text {hinge }}=0^{\circ}$ and winglet span $=7 \%$ ) to highlight the sensitivity of performances to external conditions. To assess the loads alleviation capabilities, computations are performed for this configuration adding a load factor.

\section{Aerodynamic Performances and Loads Analysis: Baseline Configuration}

\section{A. Full Aircraft and Wing Configurations: Validation of the Impact on Drag and Loads}

As mentioned previously a simplified wing configuration is used for the major part of the analysis to save precious computational time. The impact of this simplification must be assessed to be sure that the sensitivities are well captured and no significant effects are introduced when full aircraft is considered. The baseline hinge is first analysed for the two configurations: it is taken to be at the extreme limit for the airport category of the aircraft resulting in an active part that represents $7 \%$ of the wing half-span. The hinge line is considered "line of flight" i.e. aligned with the longitudinal axis of the aircraft.

The simulations are performed in the same flight conditions, only the targeted lift coefficient is adjusted to take into account that fuselage and other parts such nacelles have a non-negligible contribution to lift. Therefore, for the wing only configuration the lift coefficient is approximated to $88 \%$ of the global one for the whole aircraft and the considered mass case. This estimation comes from aerodynamic data provided by Airbus. In Fig 4 the evolution of drag with respect to cant angle variations is presented for the two configurations. It highlights that the sensitivity of aerodynamic performances are well captured by the simplified geometry. For cant angles higher than $30^{\circ}$ the sensitivity of drag for the wing configuration is slightly over estimated with respect to the complete aircraft. Observing the drag components 


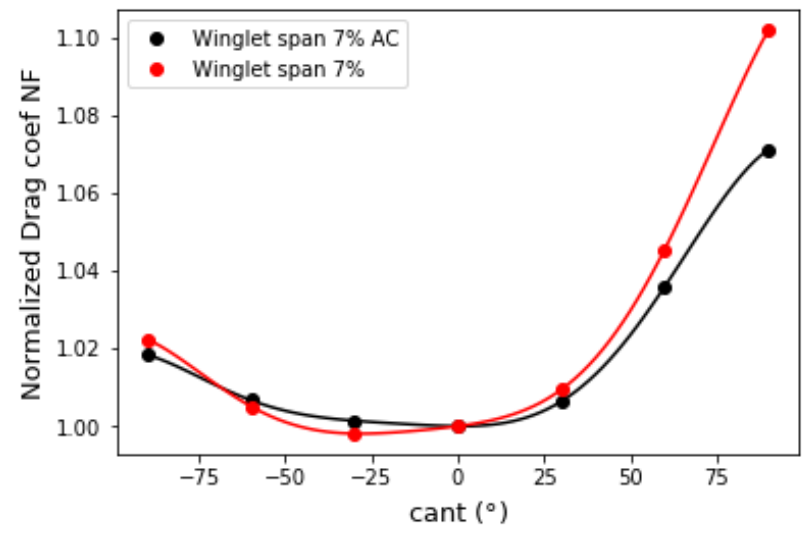

Fig. 4 Drag evolution with cant angle for complete aircraft and wing only configurations. Results are normalized by the $\delta=0^{\circ}$ value.

shows that the difference mainly comes from the wave drag that increases rapidly with cant angle for the wing alone (Fig 5). When the complete aircraft is considered, wave drag results from the wing contribution but also from the tails. Thus, the absolute total wave drag value is higher reducing the relative variation due to cant angle changes.

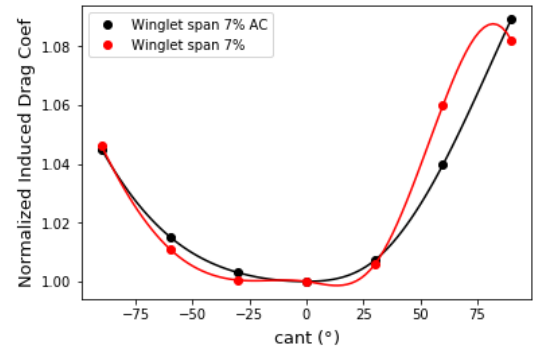

(a) Induced drag

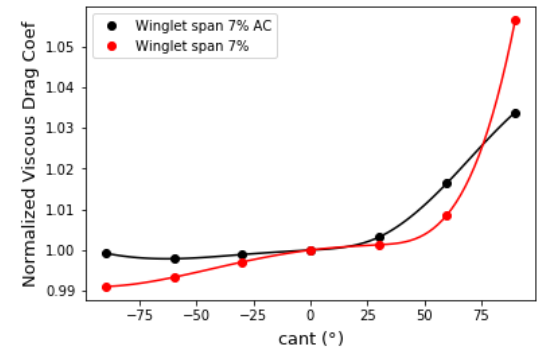

(b) Viscous drag

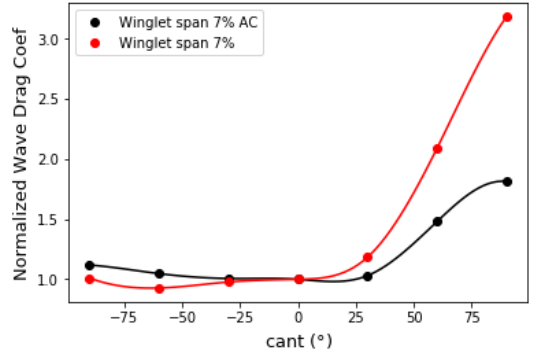

(c) Wave drag

Fig. 5 Drag components evolution with cant angle variationsfor complete aircraft and wing only configurations. Results are normalized by the $\delta=0^{\circ}$ value.

Despite the slight differences that exist between the two configurations - which was expected - results demonstrate that a control of the drag is possible by acting on the winglet deflection. However the area of interest is limited to the range $\left[-30^{\circ}, 0^{\circ}\right]$ and only little improvement are expected: less than $0.5 \%$ which is within the uncertainty level for the wing only configuration. Indeed for cant angles outside this interval the drag rises significantly preventing for any additional benefits. As it was already demonstrated [12], the improvement between the flat deflection and the slightly negative cant is due to the increase of the wing twist in the outermost part of the wing while still benefiting from a positive span effect as the apparent span increases for downward winglets when the wing bends.

Regarding loads, one of the most important parameter when sizing a wing is the root bending moment. To assess the capability of the active winglets to alleviate loads, focus is put on its evolution with respect to cant angle for the two configurations of interest in this part. Results presented in Fig 6 demonstrate that the trend is perfectly captured by the simplified configuration. Although marginal (0.4\%), a diminution of the loads level for downward pointing winglet is also highlighted on this graph. The negative cant angle deflections are preferred due to the favourable orientation of the lateral force acting on the deflected part.

\section{B. Sensitivity to Flight Conditions}

For the design point, the benefit is shown to be negligible which is not surprising given that the wing plane shape is optimized for this flight conditions. But, for off-design cases additional and more significant drag reduction are 


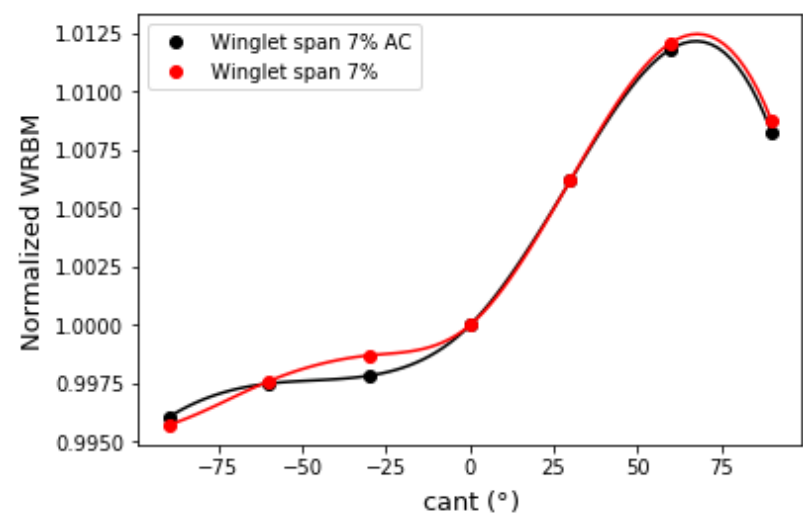

Fig. 6 WRBM evolution with cant angle variations for complete aircraft and wing only configurations. Results are normalized by the $\delta=0^{\circ}$ value.

expected as illustrated in Fig 7 For low altitude and mass the performance can be improved by almost 1\%, the benefit then decreases as weight increases. The expectation for high altitude case is reduced to marginal gains around $0.5 \%$ which represents around 1 Drag count of drag reduction. Another important feature of these graphs is that the minimum of drag for the different flight conditions spreads on a large range of cant angle values which advocates for an active winglet device.

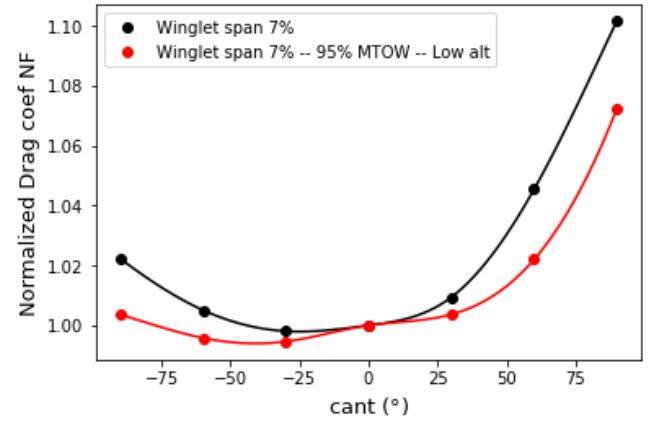

(a) Low altitude - High mass

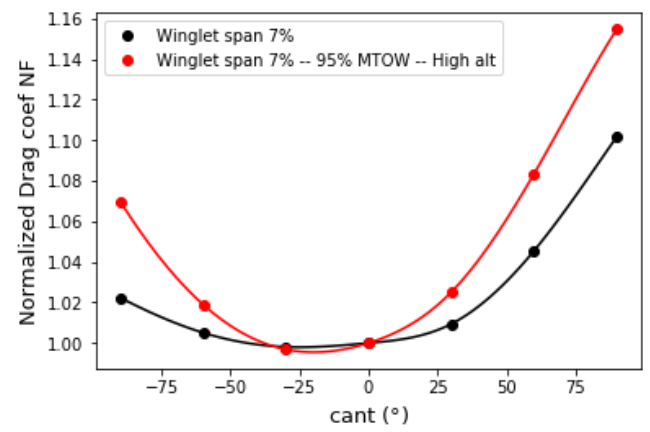

(c) High altitude - High mass

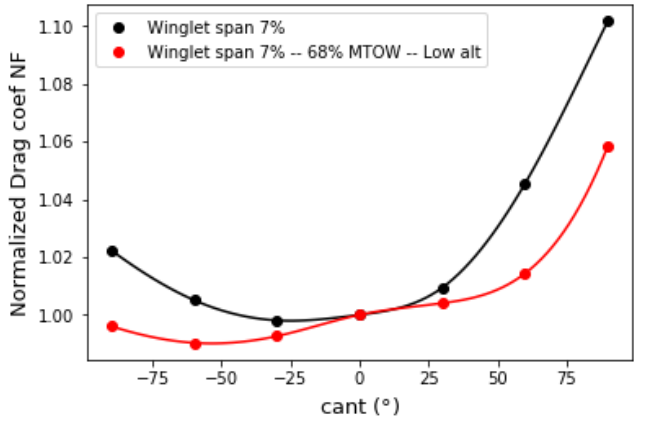

(b) Low altitude - Low mass

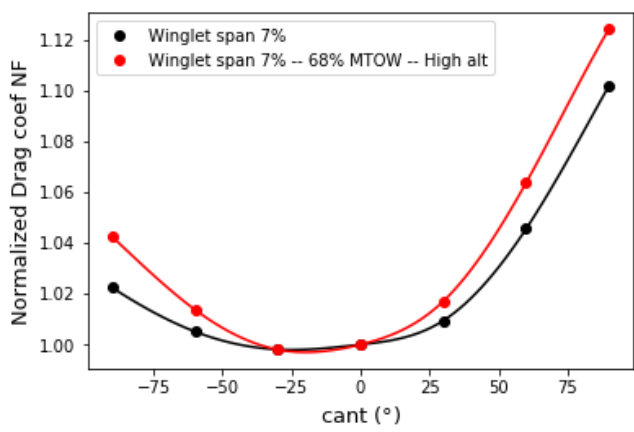

(d) High altitude - Low mass

Fig. 7 Near-Field drag evolution with cant angle for different flight conditions and mass cases. The results are compared to the design cruise conditions

The drag reduction is mainly driven by induced drag for both high and low altitudes, whatever the mass case. The observation of Fig 8 shows that the induced drag can be significantly reduced for low altitude when cant angle reaches 
values between $\delta=\left[-60^{\circ},-30^{\circ}\right]$. It can be shown that external lift distribution with smooth variation better performs regarding induced drag [22]. Observing Fig 9 it is qualitatively noticeable that $\delta=-60^{\circ}$ configuration presents a more optimal lift distribution. For high altitude cases, almost no differences exist between $\delta=-30^{\circ}$ and the baseline configuration $\delta=0^{\circ}$ while the load on the moveable part decreases drastically for $\delta=-60^{\circ}$ leading to induced drag penalties.

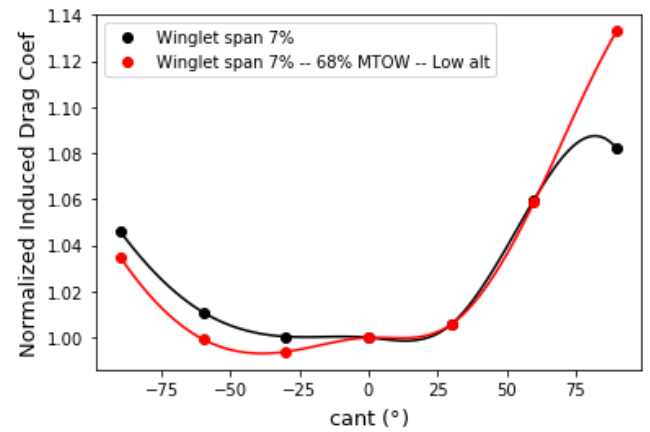

(a) Low altitude - Low mass

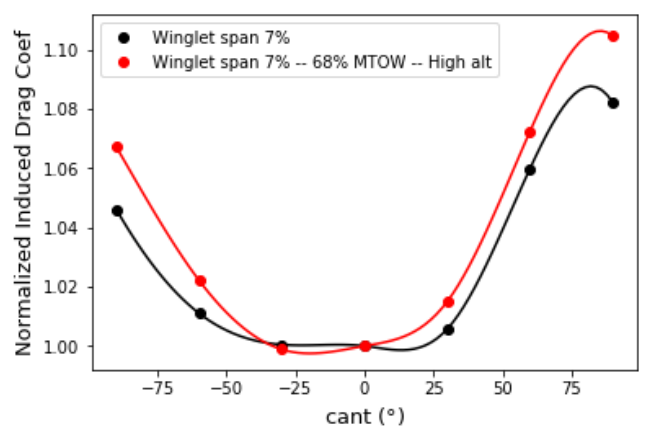

(b) High altitude - Low mass

Fig. 8 Induced drag evolution with cant angle for Low mass cases and extreme cruise altitudes.

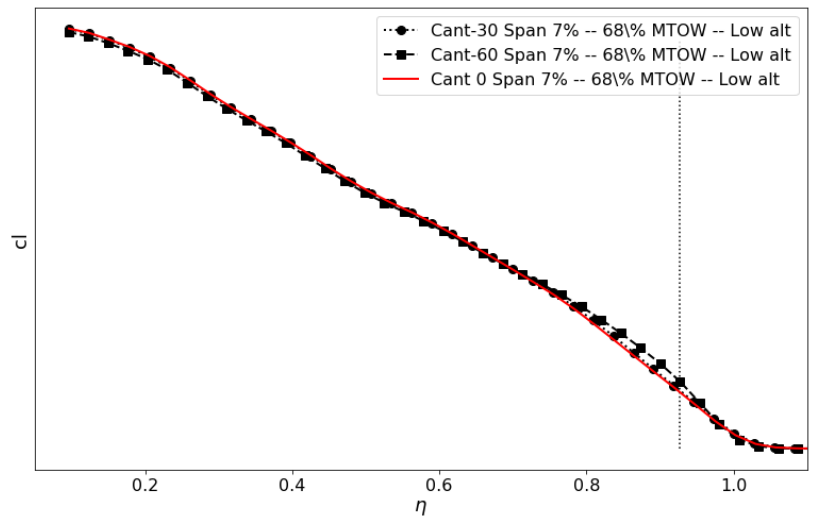

(a) Low altitude - Low mass

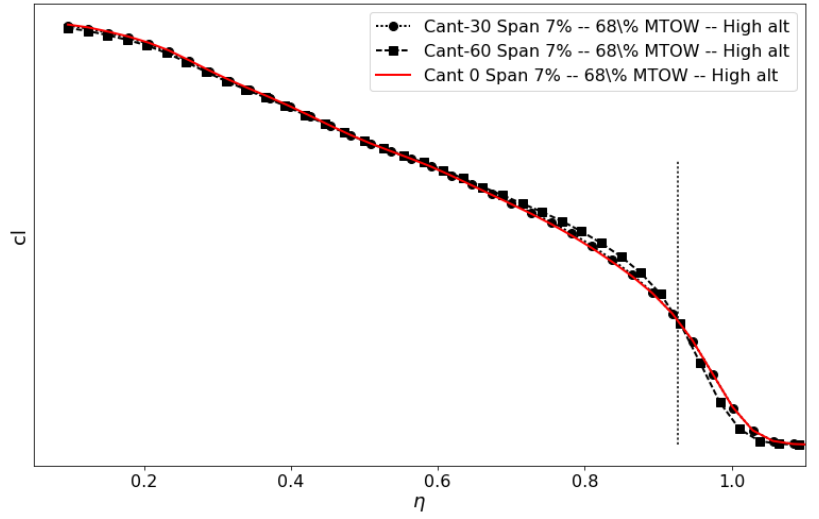

(b) High altitude - Low mass

Fig. 9 Spanwise lift distribution for low mass case and extreme cruise altitudes. The hinge location is materialized by the vertical dashed line

The actuation of the system toward negative cant deflection is shown to slightly reduce loads in cruise condition. For that particular flight point the wing is not heavily loaded and the result presented in Fig 6 lets room for a higher load alleviation capability for more severe conditions. Computations with a load factor of $1.66 \mathrm{~g}$ were performed for $\delta=0^{\circ}$ and $\delta=-90^{\circ}$ on the simplified configurations for the same flight conditions and mass case already presented. They demonstrate a capability to reduce the WRBM by around $2 \%$ (Fig 10 ). The reduction of bending moment results partially from the lateral force applied to the winglet that creates an opposite moment at the winglet root $(\eta \approx 0.93)$. The computation are not pushed further toward more important load factors because massive flow separations would occur and CFD would not be predictive. 


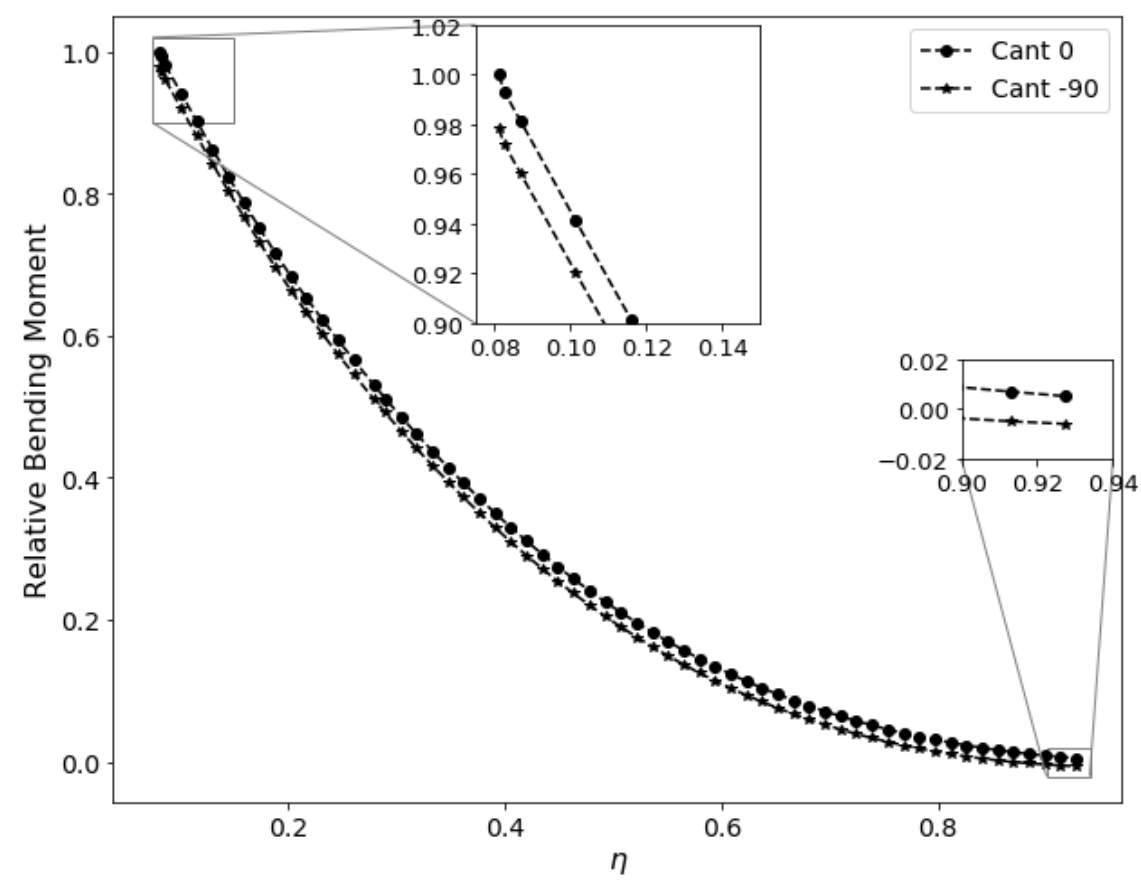

Fig. 10 Bending moment spanwise distribution for two winglet cant angles $\delta=0^{\circ}$ and $\delta=-90^{\circ}$ for a load factor of $1.66 \mathrm{~g}$ in cruise conditions.

\section{Impact of Hinge Parameters on Performances and Loads}

\section{A. Impact of Hinge Line Location}

Moving the hinge line more inward (active part $=13 \%$ half-span) increases the sensitivity of drag to cant angle deflection as shown in Fig 11a. However, it also moves the optimal deflection toward $0^{\circ}$ which means that, in that case, the actuation would be barely necessary to recover the optimal drag. It is foreseeable that for such a configuration the interesting actuation range will be reduced given that the greater lose of span when deflecting the winglet will not be compensated by the increase of wing tip twist (Fig $11 \mathrm{~b}$ ). The lift distribution along the span for the two different hinge location and $\delta=60^{\circ}$ illustrates this statement. One can observed that the lift is shifted more inward for the innermost hinge and that the lift variation close to the tip are stronger. As emphasized in [22] the induced drag evolves as the lift times its first derivative with respect to span which explains the strongest increase of drag for the large winglet.

Nonetheless, observing the lift distribution it appears that the inner hinge configuration is rather interesting for a loads point of view as lift resultant is shifted inward. Indeed, Fig 13 shows that the WRBM can be reduced by $2 \%$ when deflecting the winglet downward. This loads alleviation capability is increased with respect to the baseline configuration mainly due to the reduction of the projected span and the increase of the lateral force. Here, downward deflections are favoured due to the beneficial orientation of the lateral loads (spanwise direction) acting on the winglet that creates a moment in opposition of the one generated by the main wing as illustrated in Fig 14 .

\section{B. Impact of Hinge Line Orientation}

Fixing the hinge location to $7 \%$ and changing the orientation of the hinge line inward or outward make the drag curve to rotate around the reference value point in the clock-wise direction for positive orientation and in the opposite direction for negatively oriented hinge. The sensitivity to cant angle variation is barely affected, that means the optimal cant for minimal drag is slightly shifted toward positive values for positive orientation and toward negative values otherwise.

The orientation of the hinge line does not have significant impact on aerodynamic performances (Fig 15 - for the amplitude considered here - however, its impact on loads is more remarkable. Here again, the curves of bending moment with respect to cant angle rotates compared to the baseline hinge orientation case. For $\Lambda_{\text {hinge }}>0$, the bending 


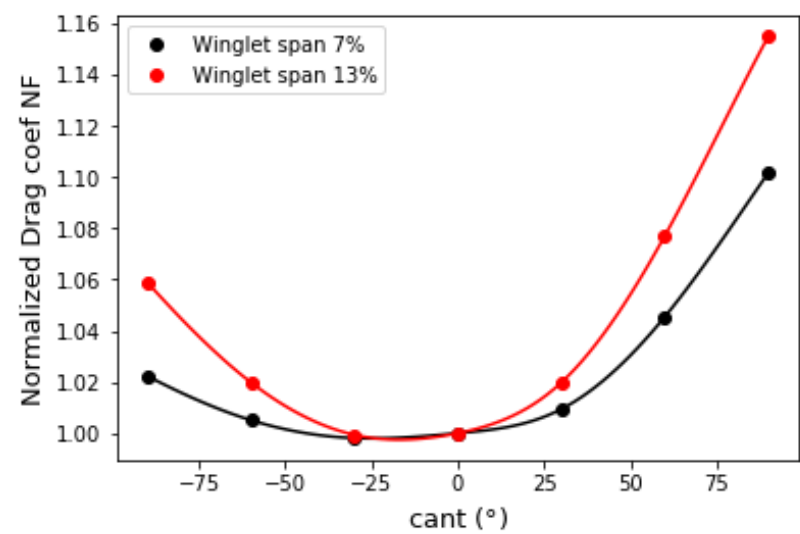

(a) Near-field drag

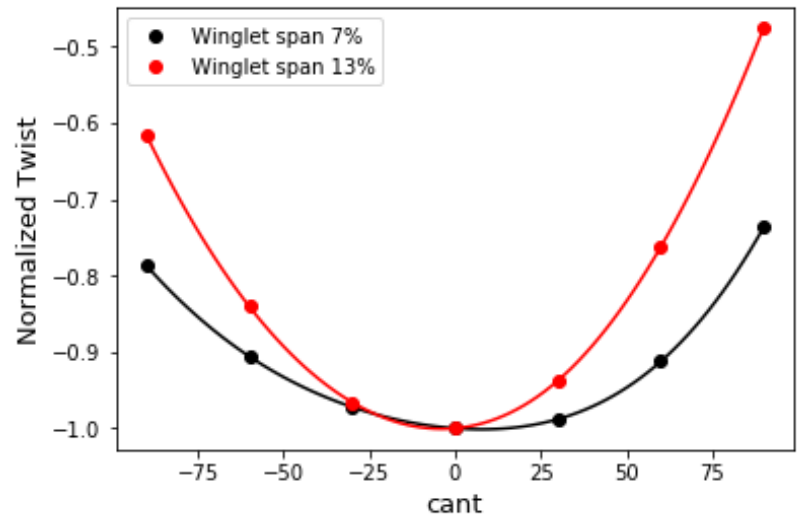

(b) Twist at hinge location

Fig. 11 Near-field drag and twist evoltion as function of winglet cant angle. Comparison between innermost hinge line and baseline configuration.

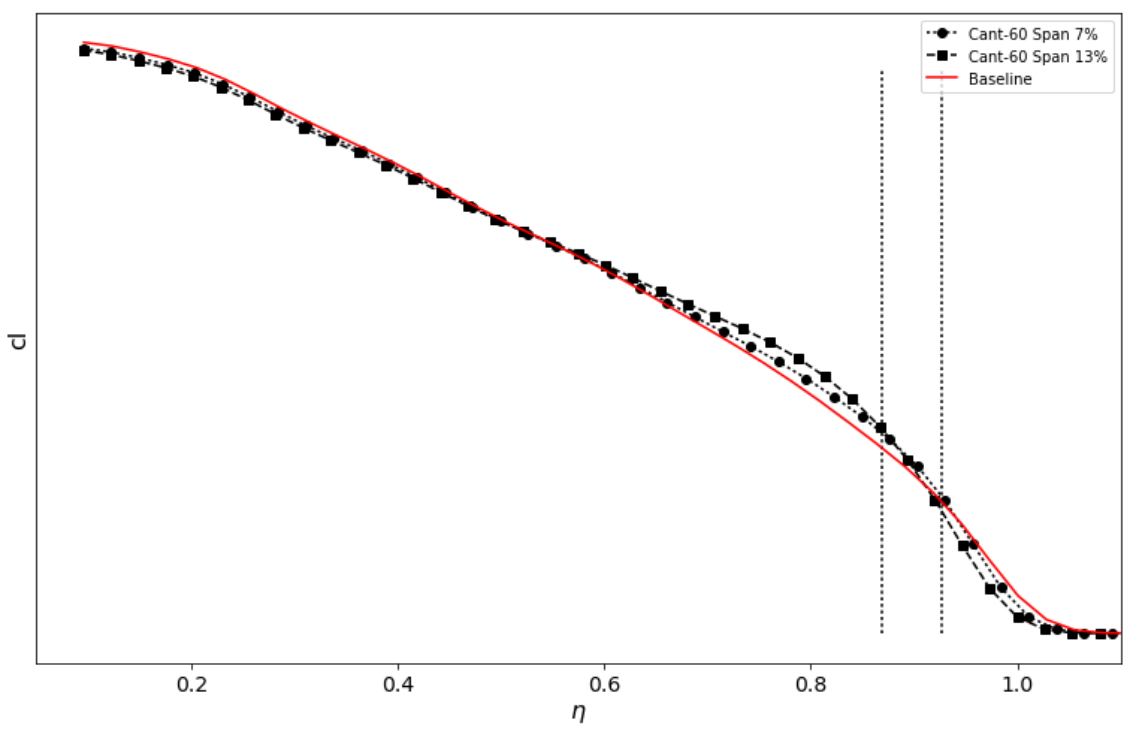

Fig. 12 Lift distribution along the span for two hinge line location and $\delta=60^{\circ}$. The baseline $\delta=0^{\circ}$ is plotted for reference. Vertical lines materialized hinges locations

moment is increased for downward pointing position because the local incidence on the winglet is higher. Lateral and vertical forces are then increased with respect to the line of flight case as illustrated in Fig 16 . In opposition for positive deflections the bending moment is reduced mainly due to the reduction of lateral load.

For hinge line oriented inward (Fig 17), the opposite occurs and loads are reduced for negative cant angle while they increase for positive values. The evolution of lateral and vertical loads on the winglet show that deflecting the winglet up leads to an increase of lateral loads respecting to the baseline hinge orientation. This increase is due to the larger local angle of attack on the winglet due to the hinge orientation. Indeed, it can be shown [10] that the rigid (i.e. without taking into account flexible effects) variation of angle of attack on the winglet $\Delta \theta$ can be related the cant angle and the orientation of the hinge line $\Lambda_{\text {hinge }}$ :

$$
\Delta \theta=-\tan ^{-1}\left(\tan \delta \cdot \sin \Lambda_{\text {hinge }}\right)
$$

Combining the observations on hinge location and hinge orientation it can be conclude that displacing and tilting the hinge inward would have significant beneficial effects on loads level if the winglet is deflected downward. However, 


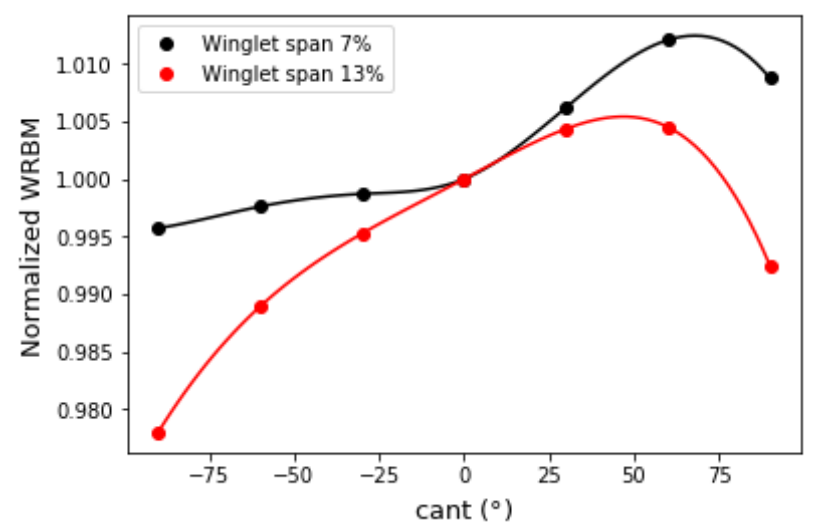

Fig. 13 WRBM in cruise condition as function of cant angle. Comparison between innermost hinge line and baseline configuration.

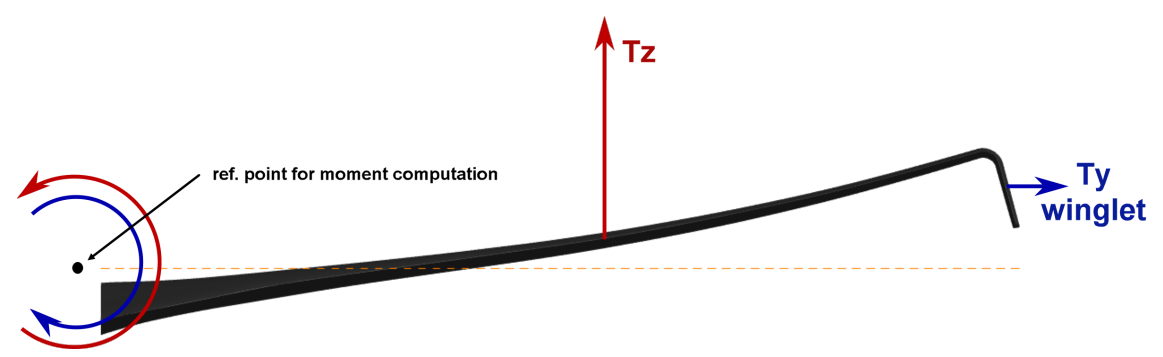

Fig. 14 Representation of the forces and WRBM acting on the main wing and winglet when folded at $\delta=-90^{\circ}$. Dashed line represents the plane $\mathrm{z}=0$ in which lies the reference point for moment computation.

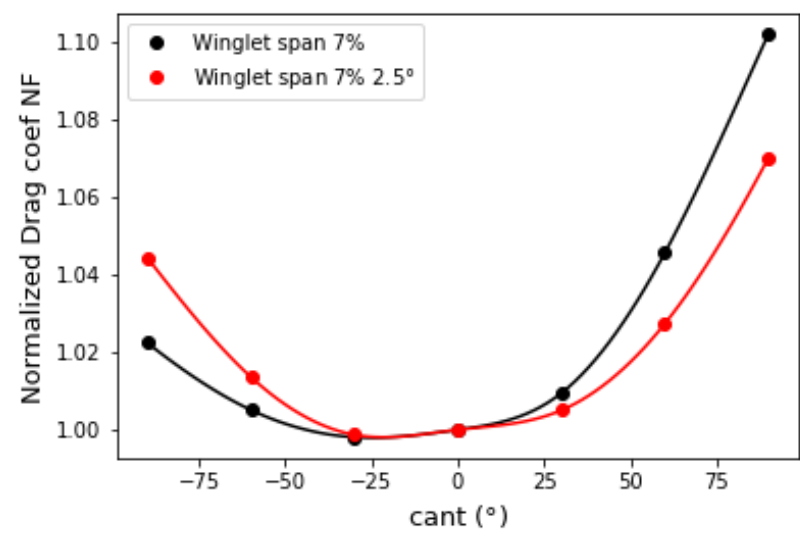

(a) Hinge orientation $=2.5^{\circ}$

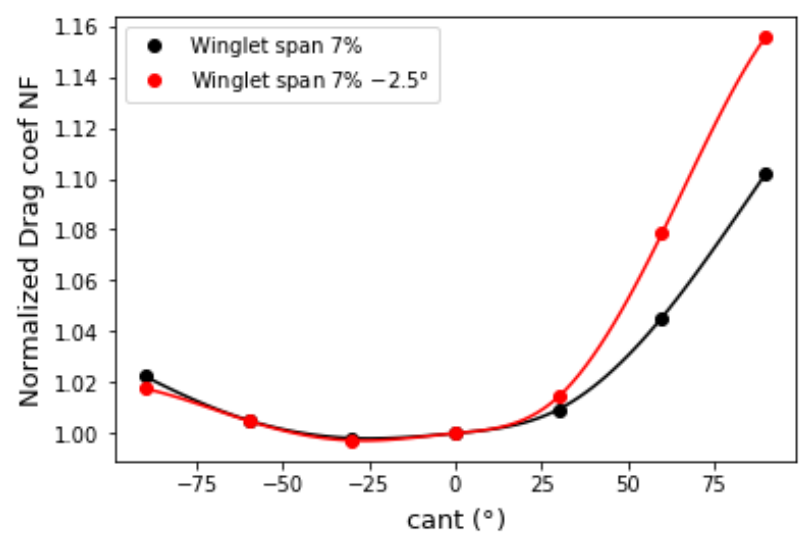

(b) Hinge orientation $=-2.5^{\circ}$

Fig. 15 Drag evolution with cant angle for two hinge line orientations. Line-of-flight hinge is used as the reference.

for a performance point of view, a larger winglet means an increase of drag sensitivity to cant angle and a smaller useful actuation range. Therefore, a trade-off must exists between action on loads and performances to have a beneficial combined effect. An intermediate winglet whose span would be around $10 \%$ of the wing span could be a good trial. 


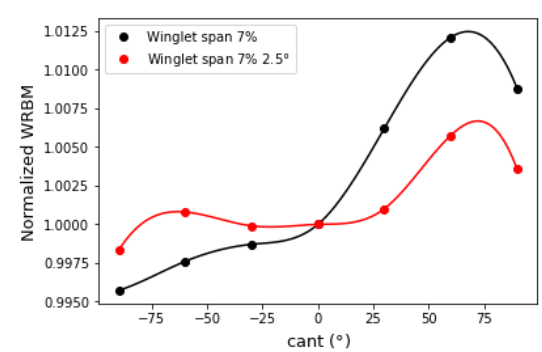

(a) WRBM

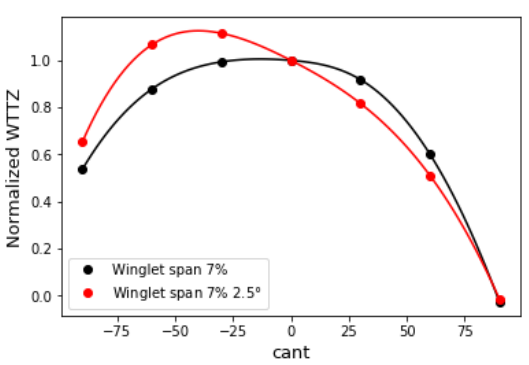

(b) Winglet vertical load TZ

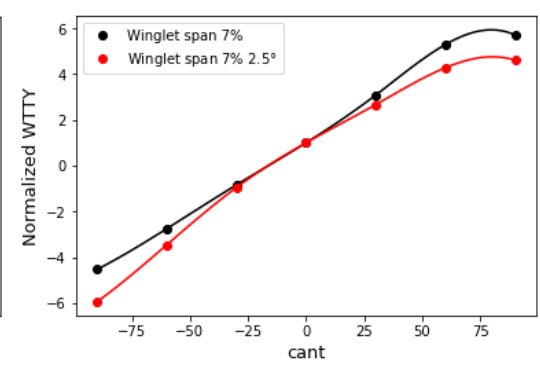

(c) Winglet lateral load TY

Fig. 16 Loads evolution with cant angle variation for $\Lambda_{\text {hinge }}=2.5^{\circ}$ compared to the baseline orientation. Results are normalized by the $\delta=0^{\circ}$ value.

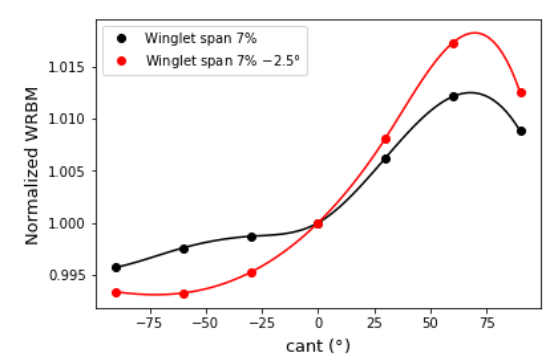

(a) WRBM

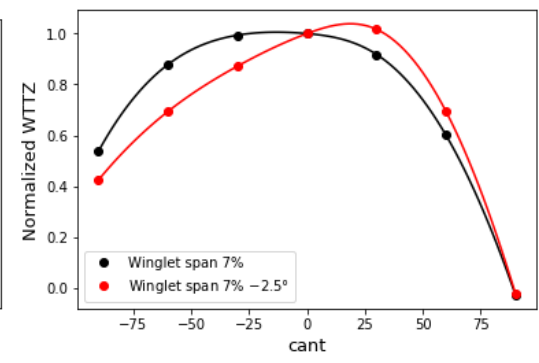

(b) Winglet vertical load TZ

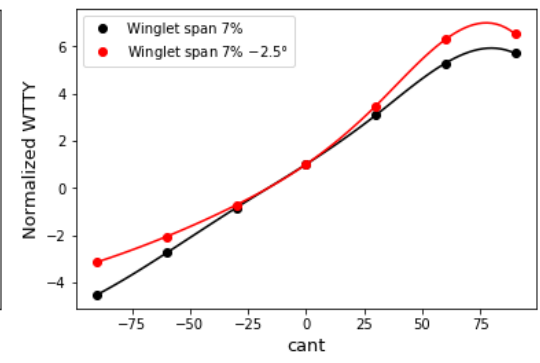

(c) Winglet lateral load TY

Fig. 17 Loads evolution with cant angle variation for $\Lambda_{\text {hinge }}=-2.5^{\circ}$ compared to the baseline orientation. Results are normalized by the $\delta=0^{\circ}$ value.

\section{Flutter Analysis}

Until now only static aeroelastic considerations are tackled to approximate the wing shape and compute aerodynamic performances and loads. But flutter consideration may challenge the conclusions established in the previous section. Flutter computations are performed for the four hinge line configurations presented in Tab 1 and for the aerodynamic design flight point conditions. But, in this paper, only configurations with $\Lambda_{\text {hinge }}=0^{\circ}$ are discussed given the weak impact of this parameters (For the considered values). First a modal analysis is performed and shows that modes switch when the winglet cant changes. For the 7\% span winglet configurations the modal shapes are plotted in Fig 18 for the six first modes for $\delta=0^{\circ}$ and $\delta=90^{\circ}$ cant configurations.

It can be observed that the first three modes exhibit similar modal shapes and frequencies (Fig $18 \&[19$ ) while the three last differ. Particularly, the fourth mode that is a bending modes for cant below $30^{\circ}$ turns to a torsion mode above. The same occurs for the fifth mode where an out-off plane movement is observed as the winglet folds (up or down). Regarding the sixth mode, the pure torsion of low cant values is progressively replaced by in-plane displacements. As already mentioned the frequencies are also impacted as illustrated in Fig 19 . While the fourth mode frequency is stable below $|\delta|=30^{\circ}$ it drops rapidly above, in opposition, the frequency of the sixth mode tends to increase with the absolute value of cant due to the change in motion type.

This alteration of the mode sequence is not without consequences on flutter onset. Indeed, for a wing only configuration the instability mainly occurs when torsion and bending modes couple. This behaviour is observed for $\delta=0^{\circ}$ configuration (Fig 20) where flutter occurs when first and sixth modes frequencies get closer.

But, as cant angle increases (in absolute value), while remaining below $30^{\circ}$, torsion mode frequency gets higher and flutter speed remains roughly identical or slightly increased. Still increasing cant angle makes torsion component to appear earlier in the frequency range (fourth mode) and flutter onsets when first and fourth mode couple reducing the critical speed (Fig 21].

Fig 22 shows the evolution of the flutter critical speed with cant angle, as the cant folds up or down above $60^{\circ}$, because the frequency of the fourth mode decreases, the flutter onset speed drops. 


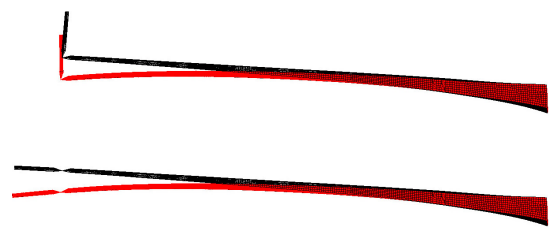

(a) Mode 1

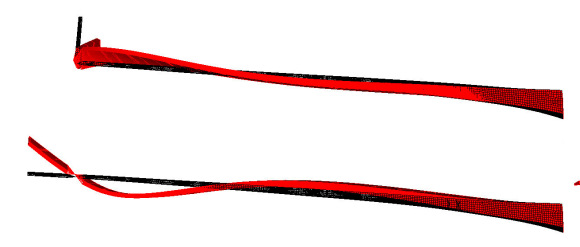

(d) Mode 4
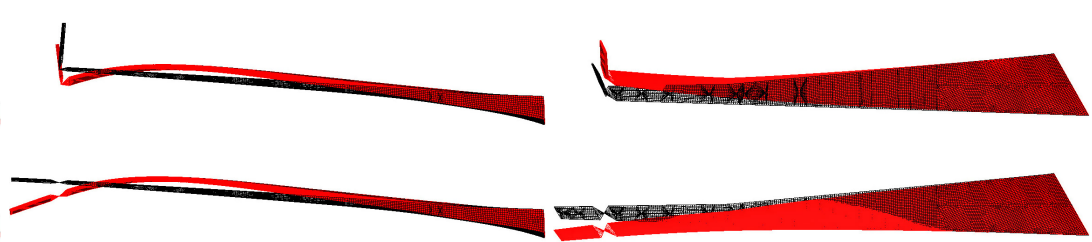

20

(b) Mode 2

(c) Mode 3

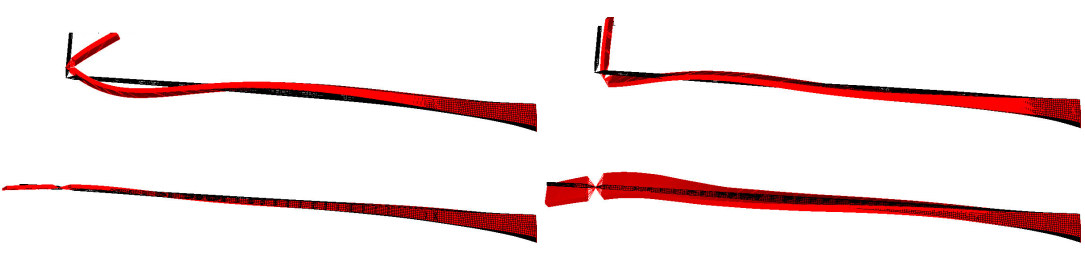

(e) Mode 5

(f) Mode 6

Fig. 18 Modes shapes for $\delta=0^{\circ}$ (down) and $\delta=90^{\circ}$ (up) and winglet span ratio $=7 \%$ configurations.
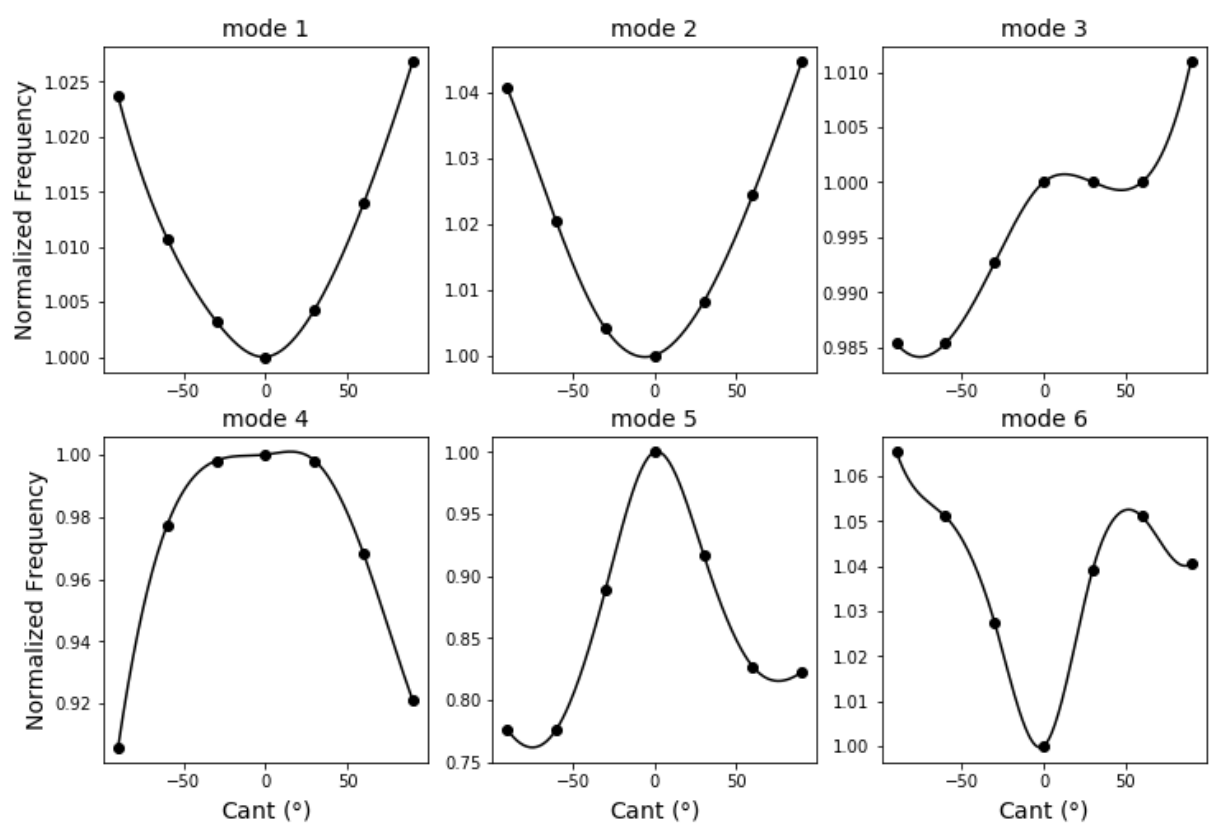

Fig. 19 First six structural modes frequencies evolution with cant angle for winglet $\operatorname{span}=7 \%$ and $\Lambda_{\text {hinge }}=$ $0^{\circ}$.

Similar behaviour is observed for the larger winglet with hinge line positioned at $87 \%$ of wing span. And some features are even exacerbated: For highly deflected cases $\left(\delta>60^{\circ}\right)$ the pure in-plane mode (mode 3 in Fig 18 ) disappears to the advantage of a combined torsion and in-plane mode that can trigger flutter instability when coupled with the first bending mode. Besides, the frequency reduces and this mode switch with the second bending mode in the mode sequence as illustated in Fig 23 that presents the shapes of the sixth first modes. As a results the flutter critical speed drops even more abruptly for high cant angle values (Fig 24 . 

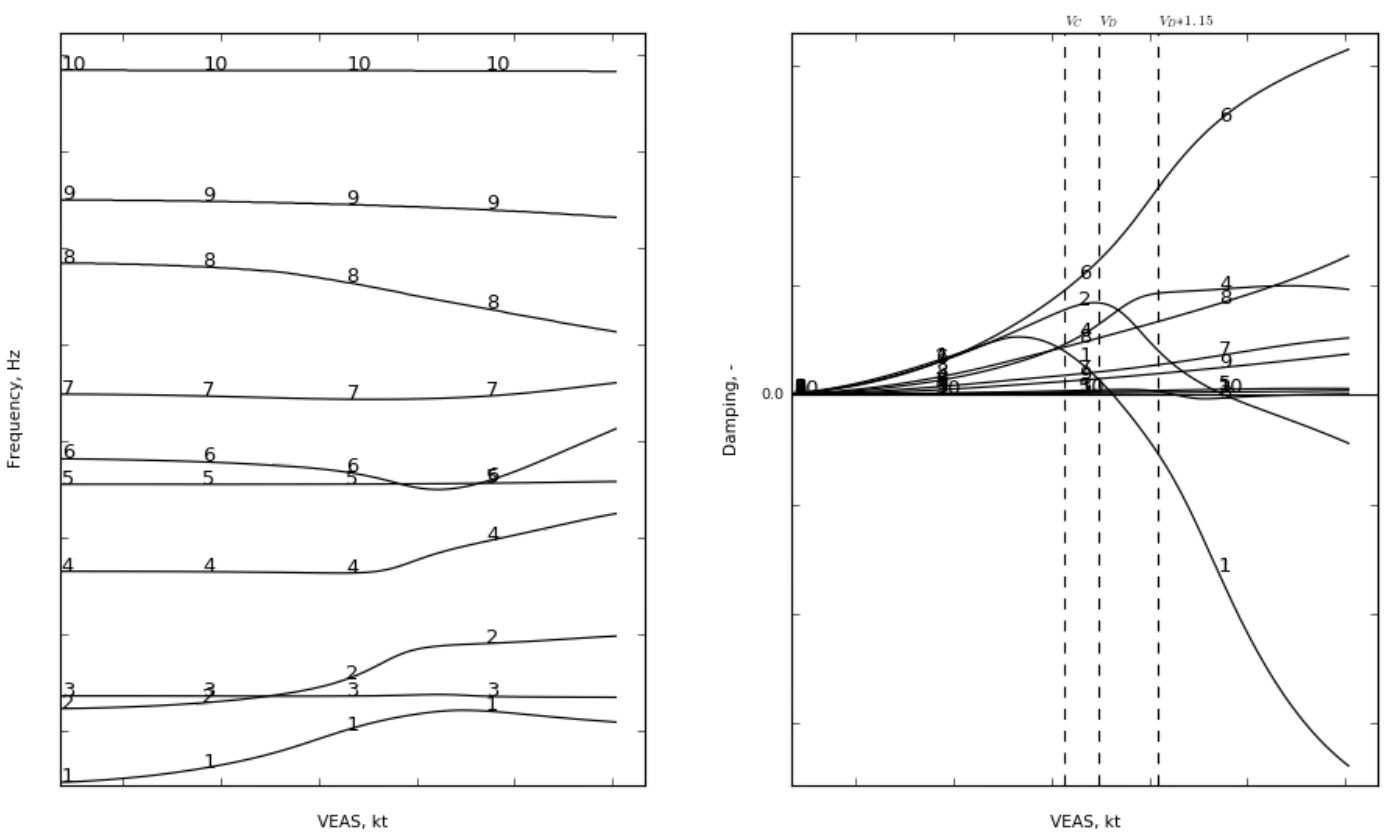

Fig. $20 \mathrm{Vf}$ and Vg plots for winglet span $=7 \%, \delta=0^{\circ}$ and $\Lambda_{\text {hinge }}=0^{\circ}$.
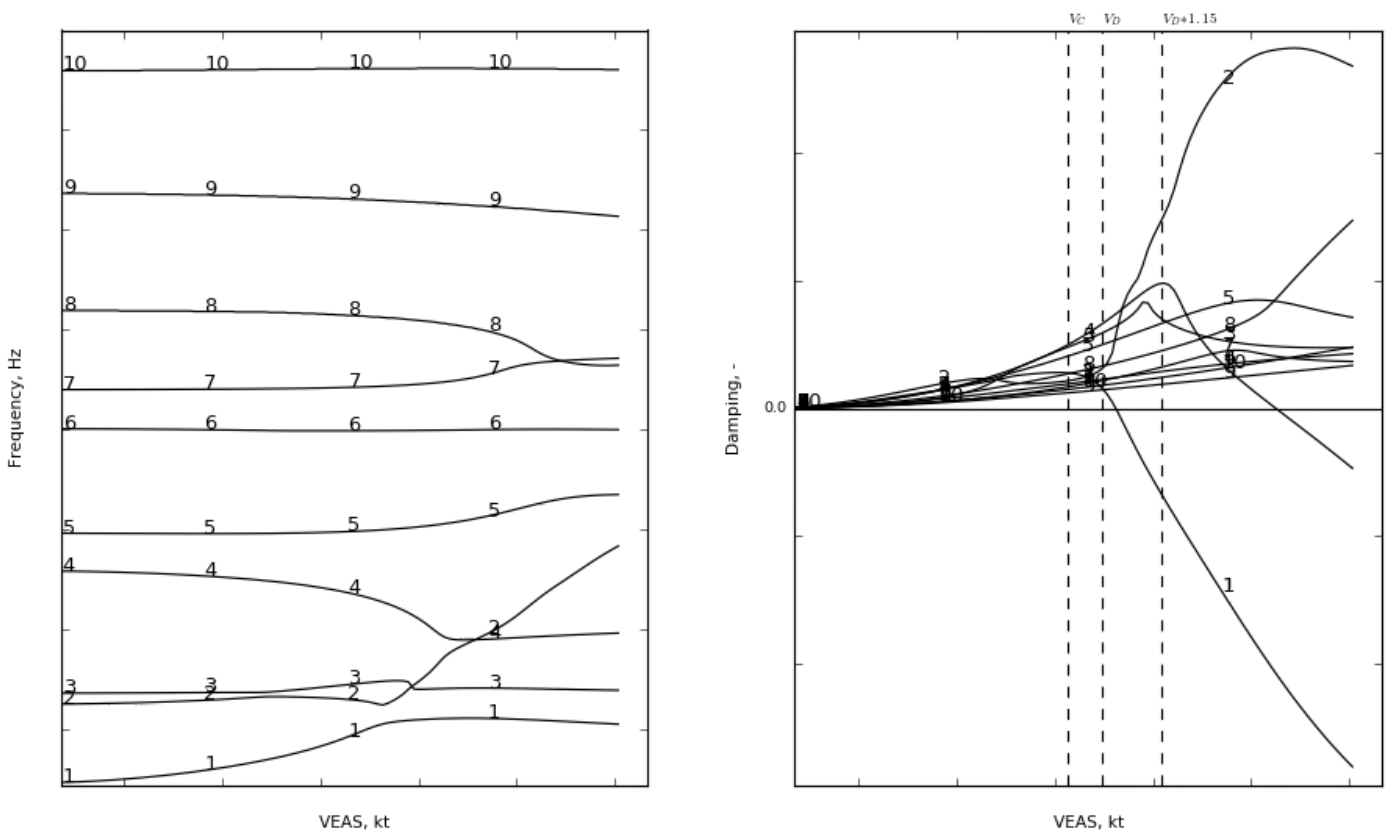

Fig. $21 \mathrm{Vf}$ and Vg plots for winglet span $=7 \%, \delta=60^{\circ}$ and $\Lambda_{\text {hinge }}=0^{\circ}$

As demonstrated, folding the winglet has massive impact on flutter characteristic for this high aspect ratio wing. The mode sequence is altered by the change of cant angles that triggers the flutter earlier or later depending on the folding angle. However, this analysis is a simplified case and a more representative configuration involving the whole aircraft with fuselage and engines modes as well as antisymmetric considerations would necessarily give different results. 


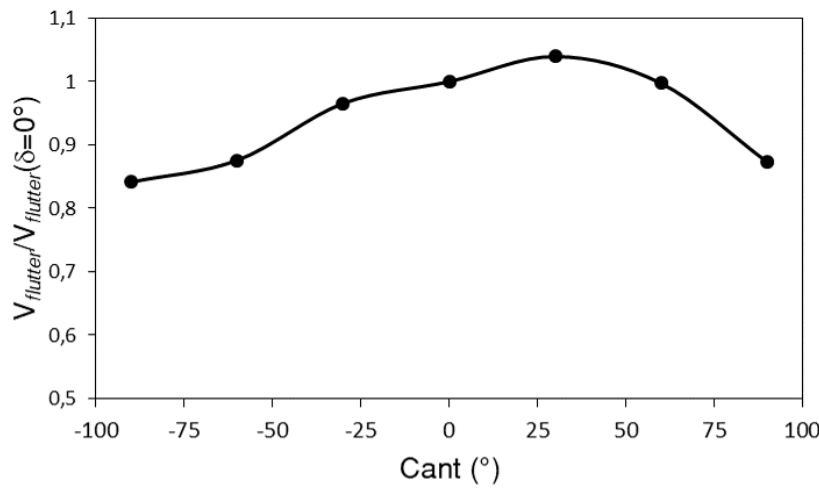

Fig. 22 Evolution of the flutter critical speed with cant angle for winglet span $=7 \%$ and $\Lambda_{\text {hinge }}=0^{\circ}$.

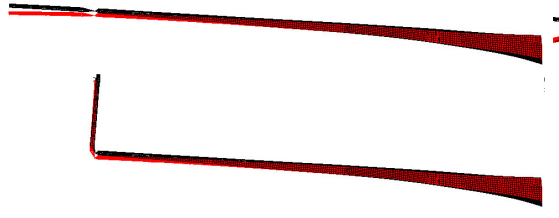

(a) Mode 1

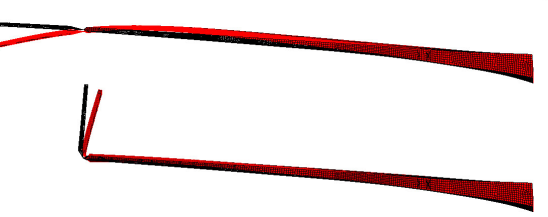

(b) Mode 2

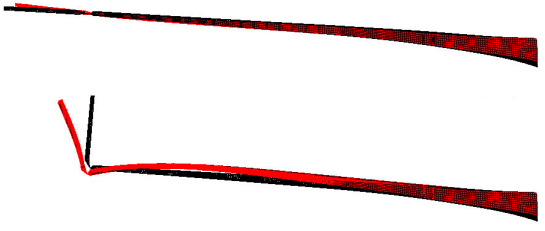

(c) Mode 3

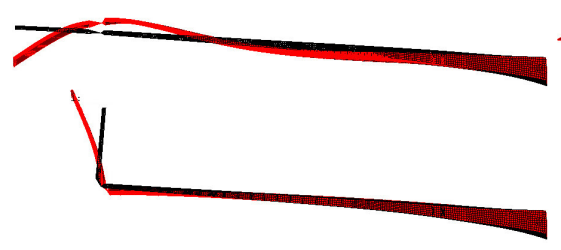

(d) Mode 4

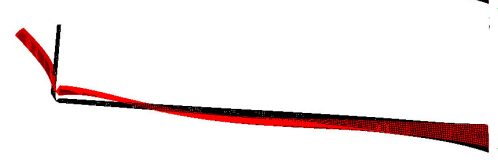

(e) Mode 5

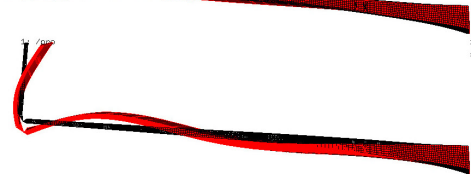

(f) Mode 6

Fig. 23 Modes shapes for $\delta=0^{\circ}$ (up) and $\delta=90^{\circ}$ (down) and winglet span ratio $=13 \%$ configurations.

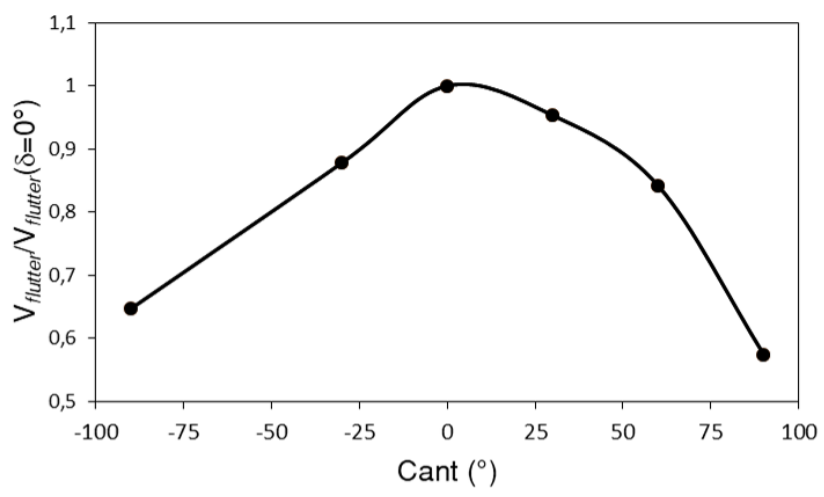

Fig. 24 Evolution of the flutter critical speed with cant angle for winglet span $=13 \%$ and $\Lambda_{\text {hinge }}=0^{\circ}$.

\section{Conclusion}

This paper evaluates the general impact of an active winglet on aerodynamic performances, loads and flutter using high-fidelity computations. Particularly, it is shown that a simplified configuration consisted of a wing clamped at the root and without engine nor fairings is sufficient to predict the major trends. It is demonstrated that the active winglet can control performances in off-design conditions and that the drag can be reduced by around $1 \%$ for certain flight points. Loads alleviation capabilities are also assessed, they are negligible for standard $1 \mathrm{~g}$ cruise but become relevant as the load factor increases. Up to $2 \%$ of WRBM reduction is reached for a load factor of $1.66 \mathrm{~g}$ in aerodynamic design 
point conditions.

In addition, this paper focuses on the influence of the hinge line location and orientation. It highlights that the spanwise location has a determinant effect on loads. The larger the winglet the larger the expected loads alleviation capability: up to $2 \%$ WRBM reduction can be reached for negative cant angles. Regarding performances aspects, the sensitivity of drag to cant variations increases with the tip size that causes the device to be less efficient in optimizing performances as the useful actuation range is reduced. The orientation of the hinge mainly impacts loads but to a far lesser extent than spanwise location. The best configuration for cruise seems to be a slightly negative angle (hinge pointing inward) to reduce loads and to shift the optimal drag toward negative cant angle values where some performance gains are predictable. Therefore, a good compromised design between loads alleviation and performance control could be a winglet with span no more than $10 \%$ of the wing span and slight negative hinge orientation. This statement should be verified through a rigorous optimization of the hinge parameters in the future.

Regarding flutter characteristics, folding the winglet leads to mode swap in the mode sequence (ordered by frequencies) with degradation of the instability onset for high cant values. This behaviour is exacerbated as hinge line is displaced inward (larger winglet) that advocates for the compromise solution of an intermediate length articulated wing-tip. For loads and performances computations, the results are validated taking into account a full model of the aircraft. However, for flutter considerations, because of the time consuming LFD process, this validation was not carried-out. That lets room for further investigations in that direction to generalize the results obtained with the simplified wing and assess how the contribution from engines and fuselage can alter the flutter behaviour.

\section{References}

[1] Anderson, J. D., Fundamentals of aerodynamics, $6^{\text {th }}$ ed., Aeronautical and Aerospace Engineering, McGraw-Hill, 2016.

[2] ICAO, “Aerodrome Design and Operations," Annex 14 to the Convention International on Civil Aviation, edited by ICAO, Aerodromes, ICAO, Montreal, Canada, June 2016, pp. 12-13.

[3] Whitcomb, R., "A design approach and selected wind-tunnel results at high subsonic speeds of wing-tip mounted winglet," NASA Technical Note, 1976.

[4] Freitag, W., and Schulze, T. E., "Blended Winglets Improve Performance,” AERO Boeing company magazine, 2009, pp. 8-12.

[5] Dees, P., Good, M. S., Sakurai, S., Kordel, J., Fox, S. J., Lassen, M. A., Fox, R. B., Walker, S. P., and Santini, G. M., "hinged raked wing tip," US Patent US2013/0099060, 2013. The Boeing Company.

[6] Barbarino, S., Bilgen, O., Ajaj, M., Rafic, Friswell, I., Michael, and Inman, J., Daniel, “A review of morphing aircraft,” Journal of Intelligent Material Systems and Structures, Vol. 22, 2011, pp. 823-877.

[7] Peter, F., and Stumpf, E., “The development of morphing aircraft benefit assessment,” Morphing Wing Technologies, 2018, pp. $103-121$.

[8] Nguyen, N., Kaul, U., Lebofsky, S., Chaparro, D., and Urnes, J., "Development of variable camber continuous trailing edge flap for performance adaptive aeroelastic wing," SAE AeroTech Congress and Exhibition, Seattle, WA, September 2015.

[9] Barriety, B., "Aircraft with active control of the warping of its wings," US Patent US6827314B2, 2004. Airbus Operations SAS.

[10] Pattinson, J., Wilson, T., and Herring, M., "High fidelity simulation of the folding wing tip for loads alleviation," International Forum on Aeroelasticity and Structural Dynamics, Saint Petersburg, Russia, 2015.

[11] Delavenne, M., Barriety, B., Vetrano, F., Ferrand, V., and Salaun, M., "Surrogate-Based Optimization of a Morphing Winglet For Flexible Aircraft," International Forum on Aeroelasticity and Structural Dynamics, Savannah, GE, June 2019.

[12] Delavenne, M., Barriety, B., Vetrano, F., Ferrand, V., and Salaun, M., "A Static Aeroelastic Analysis of an Active Winglet Concept for Aircraft performances Improvement," Fluid Structure and Sound Interaction and Control Symposium, Chania, Crete Island, August 2019.

[13] Kenway, G. K. W., and Martins, J. R. R. A., High-fidelity aerostructural optimization of the Airbus XRF1 aircraft configuration, June 2016. Technical Report.

[14] Schwamborn, D., Gardner, A. D., von Geyr, H., Krumbein, A., Ludeke, H., and Sturner, A., "Development of the DLR TAU-code for aerospace applications," International Conference on Aerospace Science and Technology, Bangalore, India, June 2008. 
[15] Menter, F., “Two-equations eddy-viscosity turbulence models for engineering applications,” Vol. 32, No. 8, 1994.

[16] Stickan, B., Bleecke, H., and Schulze, S., "Nastran Based CFD-CSM coupling in FlowSimulator," Vol. 123, 2013 , pp. $223-234$.

[17] Dussart, G., Lone, M., O’Rourke, C., and Wilson, T., "In-flight folding wingtip system: Inspiration from the XB-70 Valkyrie," AIAA SciTech Forum, San Diego, CA, January 2019.

[18] Destarac, D., and Van der Vooren, J., "Drag/Thrust analysis of jet-propelled transonic aircraft; Definition of physical drag components," Aerospace Science and Technology, , No. 8, 2004, pp. 545-556.

[19] Hassig, H., "An approximate true damping solution of the flutter equation by determinant iteration,” Vol. 8, No. 11, 1971, pp. 885-889.

[20] Wright, J. R., and Cooper, J. E., Introduction to aircraft aeroelasticity and loads, $2^{\text {nd }}$ ed., Aerospace series, Wiley, 2007.

[21] Thormann, R., and Widhalm, M., "Linear-Frequency-Domain prediction of dynamic response data for viscous transonic flows," Vol. 51, No. 11, 2013, pp. 2540-2557.

[22] Kusunose, K., and Crowder, J., "Physical properties of Maskell's inuduced drag integral," 39th AIAA Aerospace Sciences Meeting and Exhibit, 2001. 